\title{
X-Ray Study of Thermal Expansion and Transition of Crystalline Cellulose
}

\author{
Masae TAKAHASHI and Haruko TAKENAKA \\ Faculty of Home Economics, Japan Women's University, \\ 2-8-1 Mejirodai, Bunkyo-ku, Tokyo 112, Japan
}

(Received March 7, 1981)

\begin{abstract}
For the cellulose crystals I and II, the spacings and intensities of some typical Xray reflections were measured over a range of temperature from room temperature to $200^{\circ} \mathrm{C}$. The spacing $v s$. temperature curve for each reflection exhibited a distinct break at about $150^{\circ} \mathrm{C}$ for Cell I and at about $100^{\prime} \mathrm{C}$ for Cell II. The thermal expansion coefficients estimated from this curve for the (101) reflection of Cell I were $5.1 \times 10^{-5} \mathrm{~K}^{-1}$ below $150^{\prime} \mathrm{C}$ and $1.6 \times 10^{-4} \mathrm{~K}^{-1}$ above $150^{\circ} \mathrm{C}$. The intensity $v s$. temperature curve for each reflection also exhibited a break at the same temperature as that for the break of the corresponding spacing vs. temperature curve. The reason for the appearance of these breaks is not yet clear.
\end{abstract}

KEY WORDS X-Ray / Spacing / Intensity / Cellulose I / Cellulose II /

Transition /

In our previous papers, ${ }^{1,2}$ the fine structure of a cellulose crystal was investigated and a long spacing crystal structure was found. In the following study, attention is directed to thermal effects on the X-ray diffraction angle and intensity in two cellulose crystals.

\section{EXPERIMENTAL}

The lattices of the two crystal structures examined were of the types usually referred to as Cellulose I and Cellulose II. The samples used for Cell I were cotton and hemp yarns which showed clear equatorial reflections and a softwood hemlock-spruce which showed clear meridional reflections. The samples used for Cell II were a viscose rayon and merserized cotton and hemp yarns.

$\mathrm{X}$-Ray diffraction experiments on a given sample were performed at a number of temperatures from room temperature to $200^{\circ} \mathrm{C}$, using a diffractometer equipped with a high temperature attachment. The entire diffraction profile was measured after the sample was maintained at the desired temperature for $1 \mathrm{~h}$, and the profile at a specified Bragg angle as a function of temperature was determined by raising or lowering the temperature at a rate of 1.25
$\mathrm{K} \min ^{-1}$. In the latter, the diffractometer was scanned repeatedly over the range of $\pm 2^{\circ}$ about the specified Bragg angle at a rate of $1^{\circ} \min ^{-1}$. The Xray source was the nickel-filtered $\mathrm{Cu}-K \alpha$ radiation from a generator driven with $40 \mathrm{kV}$ and $20 \mathrm{~mA}$. A slit of $1^{\circ}$ was used for the divergence of radiation and a slit of $0.15 \mathrm{~mm}$ for the reception of diffracted rays.

The sample yarns were uniformly wounded on a metal plate of $25 \mathrm{~mm}$ long, $15 \mathrm{~mm}$ high, and $0.5 \mathrm{~mm}$ wide, while the sample plates of hemlock-spruce were cut into pieces of $24 \mathrm{~mm}$ long, $15 \mathrm{~mm}$ high, and $1.4 \mathrm{~mm}$ wide.

\section{RESULTS AND DISCUSSION}

Figure 1A illustrates the equatorial diffractograms of cotton (Cell I) and Figure 1B the meridional diffractograms of hemlock-spruce (Cell I), both at some selected temperatures. The following features can be seen from these diffractograms: the peak angle of the (101), (101), and (002) reflections decrease monotonically as the temperature is raised, while the peak angle of the (040) reflection first increases and then turns to decrease. For the (040) reflection the peak angle changed reversibly with a 

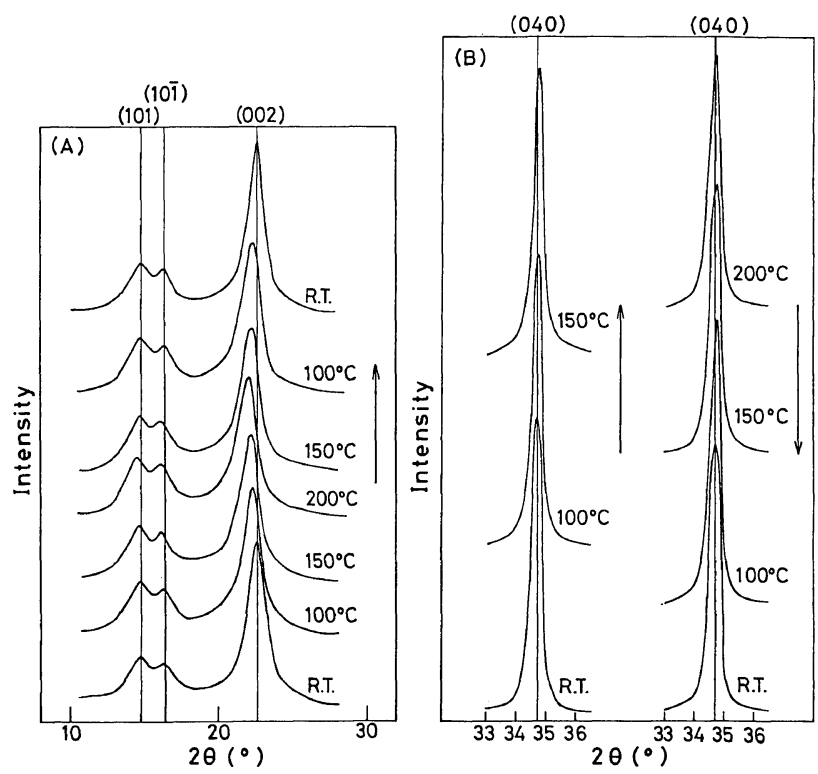

Figure 1. X-Ray diffractograms at various fixed temperatures. A, equatorial patterns of cotton (Cell I); $\mathrm{B}$, meridional patterns of hemlock-spruce (Cell I).

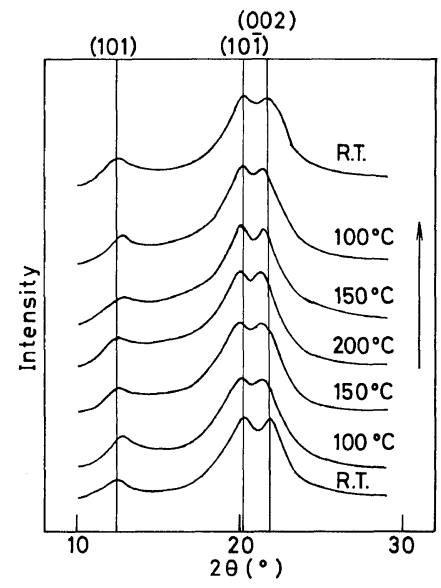

Figure 2. X-Ray diffractograms of viscose rayon (Cell II).

cyclic change in temperature, as shown in Figure $1 \mathrm{~B}$.

The X-ray diffractograms of Cell II were obtained only for equatorial reflections, since the fiber axes of the specimens used could not be placed vertically to the surface of the specimen holder. Figure 2 illustrates the diffractograms of a viscose rayon (Cell II). It is seen that the peak angles of the (101) and (002) decrease monotonically and that of the (101) re-

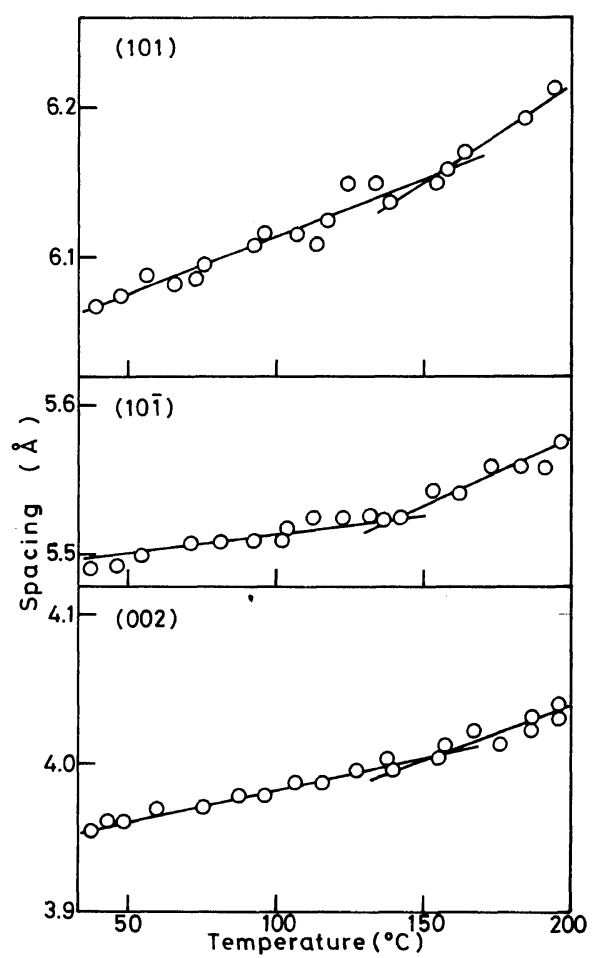

Figure 3. Spacings of the (101), (101), and (002) reflections of cotton (Cell I) plotted as a function of temperature. 
flection first increases and then decreases slightly, as the temperature is raised.

The peak angles were converted to $d$-spacings using the Bragg relation. Figure 3 shows the (101), $(10 \overline{1})$, and (002) spacings of cotton (Cell I) as a function of temperature. For each reflection, the data points can be fitted by two straight lines of different slopes which intersect at a temperature of about $150^{\circ} \mathrm{C}$. The thermal expansion coefficients determined from these lines below $150^{\circ} \mathrm{C}$ ranged from $5.1 \times 10^{-5}$ to $1.3 \times 10^{-4} \mathrm{~K}^{-1}$, with the one in the $(10 \overline{1})$ direction being the smallest. The corresponding values above $150^{\circ} \mathrm{C}$ were from $1.6 \times 10^{-4}$ to $2.3 \times 10^{-4} \mathrm{~K}^{-1}$, which are conspicuously larger than the values below $150^{\circ} \mathrm{C}$. A discontinuity in slope was found in the relative rigidity $v s$. temperature curve for a cotton linter at $140^{\circ} \mathrm{C}$ by a torsional braid analysis. ${ }^{3}$ It was also found ${ }^{4}$ from the measurement of infrared spectra of Cell I and Cell II that the relative absorbance of the $\mathrm{OH}$ stretching of intermolecular hydrogen bonds was weaker at $150^{\circ} \mathrm{C}$ than at room temperature. Our finding of the discontinuous change in the thermal expansion coefficient of Cell I at $150^{\circ} \mathrm{C}$ is consistent with these reported results, and thus may be attributed to some sharp change in the strength of intermolecular hydrogen bonds in the vicinity of $150^{\circ} \mathrm{C}$.

The (040) spacing of Cell I is plotted against temperature in Figure 4. This plot should represent thermal effects on the main-chain conformation. It is seen from the figure that, as the temperature increases to $150^{\circ} \mathrm{C}$, the (040) spacing decreases linearly, and then it turns to increase linearly. The straight lines fitting the data points below and above $150^{\circ} \mathrm{C}$ give $-6.4 \times 10^{-4} \mathrm{~K}^{-1}$ and $1.6 \times 10^{-4} \mathrm{~K}^{-1}$ for the slopes. The reason for this temperature dependence of the (040) spacing is not yet clear.

Figure 5 shows the (101), (101), and (002) spacings of Cell II as a function of temperature. The plot for the (101) reflection indicates the same behavior as the (040) spacing of Cell I. It has been reported ${ }^{4}$ that heat treatment of Cell II induces relaxation of the intermolecular hydrogen bonds, causing the crystal structure to change to an orthorhombic structure. Our data for the (101) spacing of Cell II do not contradict this reported result. Figure 5 indicates that the breaks in the spacing $v s$. temperature curves for Cell II occur at about $100^{\circ} \mathrm{C}$, regardless of the reflections.

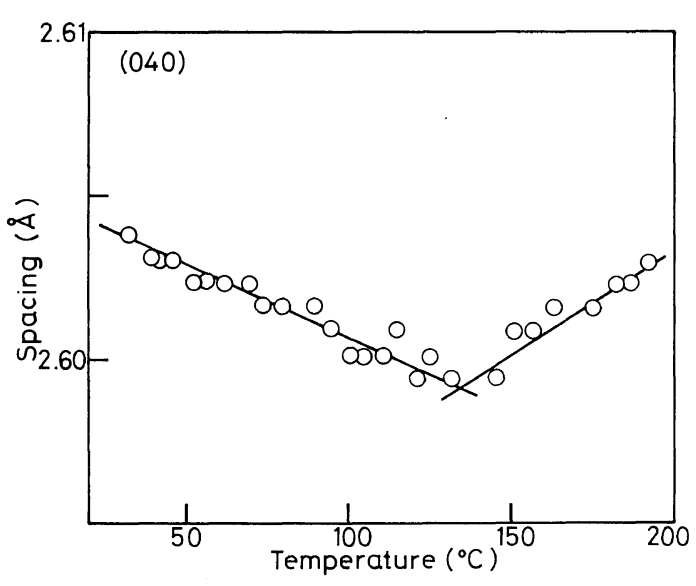

Figure 4. Spacing of the (040) of hemlock-spruce (Cell I) as a function of temperature.

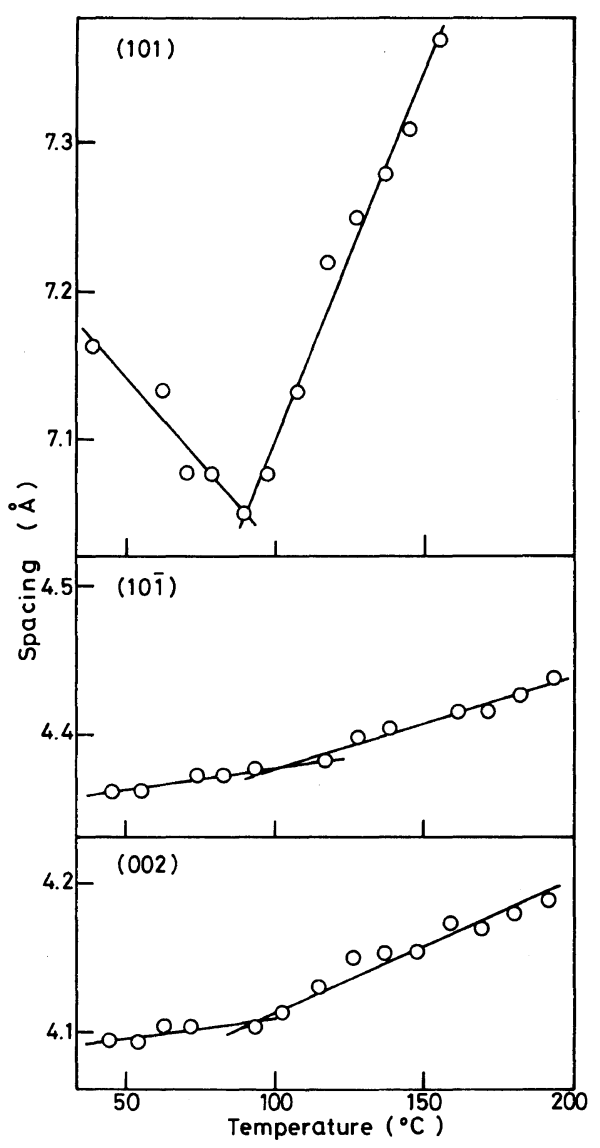

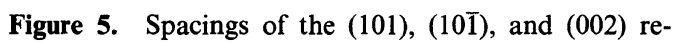
flections of viscose rayon (Cell II) as a function of temperature. 
Table I. Thermal expansion coefficients of Cell $\mathrm{I}^{\mathrm{c}}$ and Cell $\mathrm{II}^{\mathrm{d}}$

\begin{tabular}{|c|c|c|c|c|c|c|c|c|}
\hline & \multicolumn{2}{|c|}{ (101) } & \multicolumn{2}{|c|}{$(10 \overline{1})$} & \multicolumn{2}{|c|}{$(002)$} & \multicolumn{2}{|c|}{$(040)$} \\
\hline & $\alpha_{1}^{a}$ & $\alpha_{2}{ }^{b}$ & $\alpha_{1}$ & $\alpha_{2}$ & $\alpha_{1}$ & $\alpha_{2}$ & $\alpha_{1}$ & $\alpha_{2}$ \\
\hline & \multicolumn{2}{|c|}{$\mathrm{K}^{-1}$} & \multicolumn{2}{|c|}{$\mathrm{K}^{-1}$} & \multicolumn{2}{|c|}{$\mathrm{K}^{-1}$} & \multicolumn{2}{|c|}{$\mathrm{K}^{-1}$} \\
\hline Cell I & $1.3 \times 10^{-4}$ & $2.3 \times 10^{-4}$ & $5.1 \times 10^{-5}$ & $1.6 \times 10^{-4}$ & $1.1 \times 10^{-4}$ & $1.6 \times 10^{-4}$ & $-6.4 \times 10^{-6}$ & $1.6 \times 10^{-5}$ \\
\hline Cell II & $-3.1 \times 10^{-4}$ & $6.8 \times 10^{-4}$ & $6.7 \times 10^{-5}$ & $1.6 \times 10^{-4}$ & $7.9 \times 10^{-5}$ & $1.9 \times 10^{-4}$ & & \\
\hline
\end{tabular}

a $\alpha_{1}$, Thermal expansion coefficient below the transition point.

b $\alpha_{2}$, Thermal expansion coefficient above the transition point.

c Samples of Cell I used for diffraction measurements in the (101), (101), and (002) directions and the (040) direction were cotton and hemlock-spruce, respectively.

d Sample of Cell II was a viscous rayon.

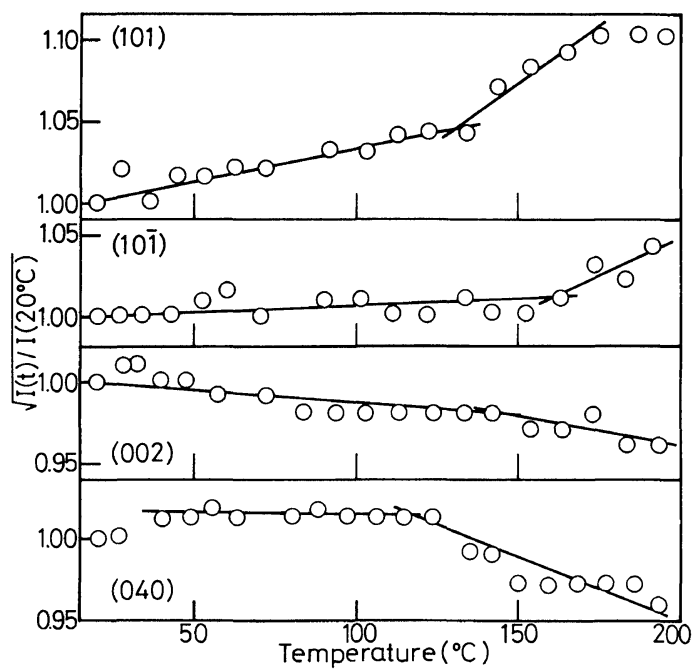

Figure 6. Square roots of the relative intensities of the (101), (101), (002), and (040) reflections of Cell I (hemp and hemlock-spruce) as a function of temperature.

In summary, the slope of the spacing $v s$. temperature curve undergoes a discontinuous change at about $150^{\circ} \mathrm{C}$ for Cell $\mathrm{I}$ and at about $100^{\circ} \mathrm{C}$ for Cell II. These temperatures are called the transition points for the respective cellulose crystals. Table I summarizes the thermal expansion coefficients for each reflection below and above the transition point.

Figure 6 illustrates the relations between the square root of relative intensity and the temperature for the (101), (101), and (002) reflections of hemp and for the (040) reflection of hemlock-spruce. The (101), (101), and (002) reflections of cotton yielded

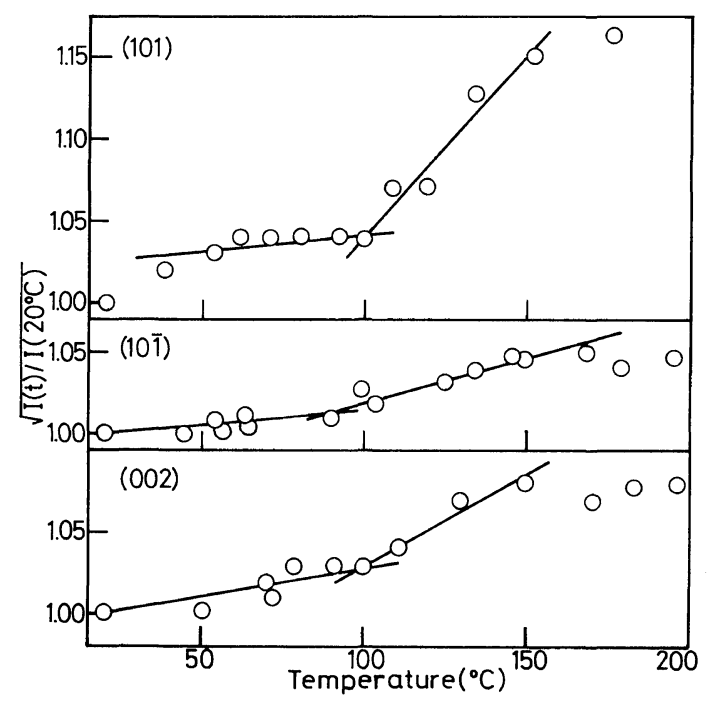

Figure 7. Square roots of the relative intensities of the (101), (101), and (002) reflections of Cell II (viscose rayon) as a function of temperature.

results similar to those obtained with hemp. The intensities of the (101) and (101) reflections increased with temperature, giving the temperature coefficients which change discontinuously in the vicinity of $150^{\circ} \mathrm{C}$ from lower to higher values. On the other hand, the intensities of the (101) and (040) reflections remained nearly constant up to about $150^{\circ} \mathrm{C}$ and then decreased as the temperature increased.

The corresponding intensity $v s$. temperature curves for Cell II are shown in Figure 7. It is seen that the intensity of each reflection increases with 
temperature and that the temperature coefficient undergoes a discontinuous change in the vicinity of $100^{\circ} \mathrm{C}$. This coefficient above $100^{\circ} \mathrm{C}$ for the (101) reflection was significantly larger than those for the other reflections.

\section{CONCLUSION}

The present study shows that the temperature coefficients of the spacings and intensities of some typical reflections of X-ray for Cell I and Cell II undergo a discontinuous change at a temperature characteristic of each crystal structure, $150^{\circ} \mathrm{C}$ for Cell I and $100^{\circ} \mathrm{C}$ for Cell II. The reason for the existence of such "transition points" is not yet clear, but it is believed that the experimental data ob- tained here deserve publication.

Acknowledgment. The authors wish to express their appreciation to Dr. P. H. Kim for his valuable comments.

\section{REFERENCES}

1. M. Takahashi and H. Takenaka, Sen'i Gakkai Shi, 35, T-99 (1979).

2. M. Takahashi and H. Takenaka, Sen'i Gakkai Shi, 36, T-223 (1980).

3. S. Nakamura, J. K. Gillham, and A. V. Tobolsky, Rep. Prog. Polym. Phys. Jpn., 13, 89 (1970).

4. A. Sueoka, J. Hayashi, and S. Watanabe, Nippon Kagaku Kaishi, 1345 (1973). 